\title{
Pyang Pyung: Sebuah Komposisi Karawitan
}

\author{
Anon Suneko ${ }^{1}$ \\ Institut Seni Indonesia Yogyakarta
}

\begin{abstract}
ABSTRAK
Karya seni "Pyang Pyung" ini merupakan apresiasi seni musik gamelan Jawa yang sesungguhnya tidak statis, namun tetap dapat dikembangkan seiring kemajuan zaman. Minoritas kêmpyang dalam instrumen gamelan merupakan potensi yang diolah sehingga karya ini merupakan wujud dari keinginan penulis untuk menunjukkan makna subyektif dari benda yang begitu kecil sehingga bisa membawa potensi luar biasa sebagai subyek seni dalam penciptaan musik. Adanya polaritas dan estetika antara siliran dan musikalitas kêmpyung sebagai jenis kombinasi dua nada, dipandang oleh penulis sebagai dua titik menarik kontras dalam dinamika penciptaan karya seni, terutama komposisi karawitan. Kêmpyang dan kêmpyung adalah dua bentuk kombinasi nada yang bisa disesuaikan untuk saling melengkapi dan keduanya berperan dalam membangun dinamika musik gamelan melalui efek suara dan karakter yang mampu diciptakan. Keduanya merupakan potensi dari substansi dasar musikal karawitan dimana kontras setiap efek suara yang nampaknya seimbang sesuai dengan persepsi estetika penyajian dan orientasi penulis melalui penciptaan komposisi musik yang menggabungkan kedua kombinasi seperti dua hal berlawanan yang saling melengkapi dalam keseimbangan harmoni komposisi musik nusantara.
\end{abstract}

Kata kunci: kêmpyang; siliran; kêmpyung; gamelan Jawa

\begin{abstract}
Pyang Pyung: A Gamelan Composition. The music artwork of "Pyang Pyung" is a matter of music appreciation in which Javanese gamelan music is not static, but it can still be developed as time advances. The minority of Kempyang role in gamelan instruments is potential that is processed in such a way that this work is a manifestation of the author wishes to point out the subjective meaning of a small object that could bring out the tremendous potential as subjects of art in the music creation. The existence and aesthetic polarity between siliran and kêmpyung musicality as two kinds of the tone combination, are seen by the author as two interesting points which are contrast in the dynamics of creating the works of art, especially Javanese gamelan music. Kêmpyang and kêmpyung are two forms of tone combination that can be aligned to complement each other and are both instrumental in establishing the dynamics of the gamelan music through sound effects and character that are able to create. Both of them are parts of the basic substance of the musical potential in which the contrast of each sound effect appears to be balanced in accordance with the presentation of aesthetic perception and orientation of the author through the creation of a musical composition that combines both combinations such as two opposites that complement to each other in the balance of harmony of an archipelago of musical composition.
\end{abstract}

Keywords: kêmpyang; siliran; kêmpyung; Javanese gamelan music

\section{Pendahuluan}

Munculnya karya baru komposisi karawitan yang inovatif, kreatif, bahkan unik tidak harus berawal dari hal yang rumit atau kompleks, namun sebuah karya seni yang baru dapat tercipta melalui pemaknaan baru terhadap kekayaan substansi dalam

\footnotetext{
1 Alamat korespondensi: Prodi Karawitan, Institut Seni Indonesia Yogyakarta. Jln. Parangtritis Km. 6,5 Sewon, Yogyakarta. E-mail: anonsuneko@gmail.com. HP: 0274375380
} 
seni karawitan tradisi, sejalan dengan kemajuan intlektualitas dan tingkat apresisasi yang selalu berkembang. Pakem sebagai wujud kristalisasi polapola baku sekaligus tuntunan dalam pelestarian seni karawitan dapat dipandang sebagai sesuatu yang melahirkan sense of art bagi para seniman melalui berbagai interpretasi dan sumber inspirasi karya seni.

Perpaduan dua nada dalam gamelan sebagai bagian kecil dalam seni karawitan berkaitan erat dengan teknik permainan ricikan tabuh kalih seperti gênder, bonang, dan gambang dalam orientasi nilai estetik dalam musikalitas gamelan. Perpaduan dua nada diklasifikasikan menurut perbedaan jarak antara dua nada dalam gamelan yang meliputi: (a) Gêmbyang, merupakan pola perpaduan dua nada yang berjarak empat nada; (b) Pêndhawan, adalah pola perpaduan dua nada yang berjarak tiga nada; (c) Kêmpyung, merupakan pola perpaduan dua nada yang berjarak dua nada; (d) Gêmbyung, yakni pola perpaduan dua nada yang berjarak satu nada; dan (e) Siliran, merupakan pola perpaduan dua nada yang kedudukannya berurutan sehingga tidak ada jarak di antara kedua nada tersebut (Gambar 1).

Konsep-konsep seperti di atas telah menarik beberapa peneliti dan seniman untuk meneliti atau membuat karya. Beberapa di antaranya adalah penelitian Prasetya (2006) mengenai Gembyang dan Kempyung dari perspektif fisika bunyi. Berdasarkan penelitiannya disimpulkan bahwa suara gembyang dan kempyung nyaman didengarkan karena bunyi tersebut menghasilkan efek pelayangan yang oleh pendengar Jawa dirasakan nyaman dan enak didengar (Prasetya, 2006). Sementara itu dalam wujud karya seni, Subawa (2007) telah membuat komposisi karawitan Salah Gumun. Komposisi ini diolah dari bunyi instrumen yang dihasilkan oleh Siliran.

Siliran menghasilkan efek bunyi khas yang salah satunya bisa diciptakan melalui tabuhan instrumen kêmpyang sebagai salah satu penanda

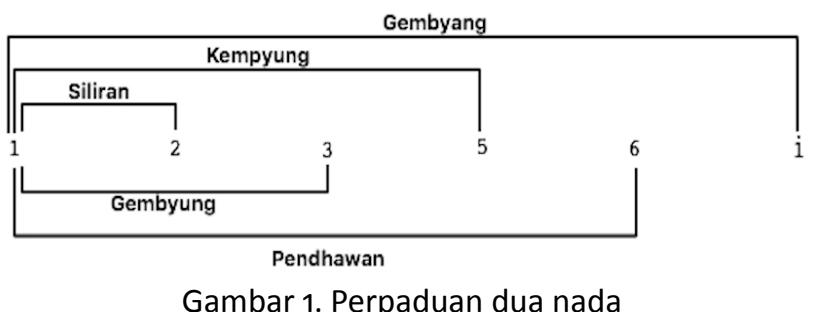

Gambar 1. Perpaduan dua nada struktur / kolotomik suatu gending. Bunyi kêmpyang dan kêthuk yang bergantian secara periodik merupakan bagian dari padhang-ulihan, tanyajawab musikal serta aksentuasi yang diekspresikan bersama-sama dengan instrumen kênong, kêmpul, siyem dan gong.

Kêmpyung sebagai salah satu bentuk kombinasi dua nada menghasilkan efek bunyi yang secara kualitatif lebih harmonis hasil perpaduannya sehingga aplikasi pola kombinasi ini lebih sering dijumpai dalam teknik instrumen tabuh kalih maupun alternatif garap.

Polaritas eksistensi dan estetis musikalitas antara siliran dan kêmpyung sebagai dua pola perpaduan nada, dipandang oleh penulis sebagai kontras dua hal yang menarik dalam bangunan dinamika sajian karya seni musik khususnya gamelan Jawa.

Kêmpyang yang terbentuk melalui perpaduan nada nêm dan barang dapat diterapkan dalam ketiga pathêt dalam laras pelog yakni: pathêt lima, pathet nêm, dan pathêt barang, memunculkan kontras musikal dalam struktur kolotomik suatu gending. Kêmpyung diterapkan secara lebih beragam dalam harmonisasi pada wilayah ritme, melodi, maupun teknik permainan instrumen ngajêng/ tabuh kalih. Melalui efek suara yang harmonis, kêmpyung mampu ditempatkan pada nada-nada seleh atau titik berat nada sehingga keberadaannya lebih sering dirasakan dalam harmoni musik karawitan.

Kêmpyang dan kêmpyung merupakan dua bentuk perpaduan nada yang dapat disejajarkan untuk saling melengkapi dan sama-sama berperan dalam membangun dinamika dalam musik karawitan melalui efek bunyi, maupun karakter yang mampu dimunculkan. Keduanya merupakan bagian dari substansi dasar dalam karawitan yang pada kenyataannya sekarang kurang diekspose bahkan hanya dianggap tidak penting bahkan atau sêpele.

Minoritas peran instrumen kêmpyang dalam orientasi estetis musikalitas karawitan tradisi Jawa memotivasi gagasan penulis untuk menciptakan suatu karya seni komposisi karawitan Pyang Pyung, penggalan suku kata terakhir dari kêmpyang dan kêmpyung sebagai subjek penciptaan karya seni musik. 
Karya musik ini akan mempresentasikan lintas peran kêmpyang yang semula hanya merupakan disonansi pada ruang-ruang kecil dalam sektor kolotomik gending ke peran yang lebih luas melalui optimalisasi potensi efek kêmpyang. Kêmpyang dan kêmpyung sebagai bentuk perpaduan harmonis yang saling melengkapi keberadaannya dalam menciptakan titik keseimbangan baru sebagai alternatif orientasi estetis musikalitas dalam komposisi karawitan.

\section{Landasan Penciptaan}

Dasar penulisan musik karawitan terdiri atas tiga tingkatan sebagai berikut: (1) Penulisan musik dengan menggunakan medium tradisi dan idiom tradisi; (2) Penulisan musik dengan menggunakan medium tradisi tetapi dengan idiom baru; (3) Penulisan musik dengan menggunakan medium baru dan idiom baru (Hastanto, 1997). Karya komposisi karawitan "Pyang Pyung" ini digarap dengan menggunakan medium tradisi dan idiom baru. Gamelan sebagai medium tradisi akan menjadi media utama penulis dalam pengungkapan ekspresi yang dalam penggarapannya akan mengembangkan idiom tradisi sekaligus menggabungkan idiom baru untuk menciptakan nuansa lain dari suatu karya komposisi karawitan.

Prabot garap dalam konvensi karawitan tradisi adalah perangkat lunak (software) yang sifatnya imajiner yang ada di benak seniman pengrawit, baik berwujud gagasan atau vokabuler yang telah lama terbentuk oleh tradisi. Rahayu Supanggah menyebut teknik, pola, irama dan laya, laras, pathet, konvensi dan dinamik sebagai prabot garap (Supanggah, 2009: 224). Keseluruhan elemen garap tersebut merupakan dasar penggarapan perpaduan dua nada yang sekaligus merupakan refleksi gagasan maupun vokabuler yang dimiliki penulis baik tradisi maupun modern dalam suatu presentasi estetis musikalitas.

Referensi gending-gending Jawa, céngkok, wilêdan dalam beberapa teknik permainan instrumen garap merupakan salah satu landasan penciptaan menempatkan gamelan sebagai bahan dasar yang akan digarap dalam sebuah karya komposisi karawitan.
Landasan dalam presentasi karya musik gamelan yang dikembangkan dengan idiom baru ini dapat digali salah satunya melalui pendalaman teknik mengaransemen tingkat dasar seperti: filler (isian), repetisi (pengulangan), augmentasi (pelebaran), diminusi (penyempitan), imitasi (peniruan), sekuen dan elise (pengurangan). Pendalaman unsur musikal yang meliputi ritme, melodi, dan harmoni disesuaikan dengan kebutuhan abstraksi struktur dalam komposisi karawitan. Ritme merupakan elemen waktu dalam musik yang dihasilkan dari durasi serta aksen. Pola ritme adalah salah satu aspek dari struktur dasar musik yang meliputi antara lain batteri rhythmic, tone colour, dan acent. Pola ritme merupakan salah satu wujud sebagai pedoman cara memainkan struktur ritme dari keseluruhan aspek ritme yang bersifat kompleks (Salim, 2010).

Bebarapa referensi, metode, serta pengalaman estetis yang diaplikasikan ke dalam garapan musik yang bermedia tradisi sehingga percampuran itu akan membantu pembentukan karakter karya musik yang mampu merepresentasikan karakter individual penulis.

\section{Konsep Penyajian}

Komposisi karawitan Pyang Pyung menggunakan format sajian mandiri sehingga penyajiannya tanpa berkaitan dengan seni pertunjukan lain. Presentasi pengembaraan kedalaman estetis musikalitas ini menggunakan media utama gamelan dengan percampuran idiom tradisi dan modern sebagai alternatif pengembangan format musik komposisi karawitan yang inovatif dan berorientasi pada nuansa kekinian. Laras Slendro menjadi alternatif laras yang dipilih sebagai media penjelajahan kedalaman estetis musikal pada pola kêmpyang dan kêmpyung dalam karawitan. Adapun instrumen yang digunakan dalam karya ini meliputi: Gênder barung, Gênder pênêrus, Slêntêm, Kêndang agêng, Kêndang batangan, Kêtipung, Gambang, Sitêr, Rêbab (dua buah), Saron (2 buah), Kêthuk, kênong, Kêmpul, Suwukan, dan Gong, Viola, Flute, Bonang Barung, Bonang Pênêmbung, Maracas, Triangle. 
Konsep perwujudan karya musik ini mengacu pada asas substansi aksidensif dimana pola-pola baku dalam kaidah tradisi diberi ornamen-ornamen tanpa menghilangkan identitas substansi tradisi. Ornamen-ornamen diwujudkan dari idiomidiom modern seperti olah ritme atau sukat, pengembangan, pemendekan, pengulangan, dan lain sebagainya dengan menyisakan identitas yang masih dapat dilacak melalui penginderaan audien.

Sebagai bagian dari bentuk seni pertunjukan maka sajian karya ini didukung oleh tata teknis pementasan yang meliputi tata setting panggung dalam kaitannya dengan penempatan instrumen yang menyelaraskan nilai fungsi dan peran, kenyamanan dan estetika visual, penerapan konsep tata lampu general lighting, tata busana pemain yang disesuaikan dengan nuansa musik yakni Jawa modern.

\section{Proses Penciptaan}

Proses perwujudan karya berjudul Pyang Pyung ini melalui serangkaian proses yang terdiri dari empat tahapan yakni: eksplorasi, eksperimentasi, aplikasi, dan tahap penyajian.

\section{Eksplorasi}

Potensi serta eksistensi perpaduan dua nada siliran dan kêmpyung diamati melalui pengamatan data-data auditif pada rekaman sajian gending Jawa, pengamatan secara langsung maupun melalui eksplorasi langsung penulis pada instrumen gamelan sesuai dengan kebutuhan.

Efek bunyi siliran yang kurang harmonis dihadirkan melalui perpaduan dua nada berdampingan merupakan elemen penting pembentuk dinamika sajian musik karawitan meskipun dalam porsi yang minimalis. Dalam pemikiran penulis yang memandang minimalisasi peran disharmonis dalam karawitan sebagai sebuah potensi, keseimbangan yang terbentuk dari penonjolan siliran merupakan cara alternatif yang dapat digunakan untuk menciptakan rasa baru didunia penciptaan komposisi karawitan.

\section{Eksperimentasi}

Penulis berimajinasi tentang komparasi efek bunyi, karakter, intensitas, potensi dua pola perpaduan nada sebagai dua hal yang berlawanan namun sebenarnya saling melengkapi keberadaannya dalam suatu kerangka komposisi karawitan. Pada tahap berikutnya penulis mengadakan serangkaian eksperimen melalui ricikan gêndèr untuk mencari alternatif pertemuan dua nada yang akan dilibatkan dalam mempresentasikan karya musik ini.

Penggunaan ricikan gender sebagai alternatif media yang dapat mewakili lebih dari satu oktaf laras sléndro bertujuan untuk mencapai efektivitas improvisasi beberapa kemungkinan perpaduan nada-nada. Melalui improvisasi, seseorang diberikan kebebasan dalam mengolah maupun menentukan apa saja yang menjadi pilihannya, melepaskan ikatan yang membelenggu untuk bebas bergerak, merentangkan gagasan yang ada dalam idenya untuk mengepakkan sayap berkelana atas kemauan idenya, dan mengembangkan pikirannya untuk menuju alam bebas tidak terikat dalam satu ikatan. Kebebasan melakukan berbagai alternative baik pada insrumen yang akan digunakan dalam merealisasikan karya atau-pun mencoba hal-hal baru dari berbagai macam kemungkinan (Warsana, 2012).

Di dalam komposisi ini penulis mencoba menerapkan beberapa cara untuk menciptakan nuansa unik dari sebuah garapan komposisi karawitan. Tabuhan kempyang dalam garap komposisi laras slendro merupakan hal di luar kebiasaan karena biasanya tabuhan kempyang hanya berlaku pada permainan gamelan pada laras pelog sehingga terciptalah perpaduan efekefek siliran dan kêmpyung yang memberi warna khas pada garapan ini. Selain itu, penerapan kontras laras seperti yang terjadi pada permainan gamelan slendro pada gamelan juga menjadi strategi penulis dalam menciptakan karakter unik garapan ini. Meskipun gemelan yang digunakan berlaras sléndro, akan tetapi vokalnya tidak berlaras sléndro, bisa berlaras degung, madenda, mandalungan, atau bahkan bisa multilaras yakni campuran semua laras yang terdapat dalam karawitan Sunda (Saepudin, 2015). 
Pengolahan kêmpyang dan kêmpyung melalui teknik-teknik seperti filler, sekuen, repetition, elise dan perombakan terhadap motif, gatra, lagu maupun ritme semakin mendukung eksperimentasi sebagai salah satu cara dalam menciptakan nuansa baru dalam garapan komposisi karawitan.

Situasi, kondisi, suasana internal maupun eksternal yang mendukung merupakan hal yang memberi pengaruh positif terhadap mood dalam proses eksperimentasi, baik secara langsung melalui praktek melalui instrumen maupun imajinatif (angan-angan) yang kemudian didokumentasikan secara tertulis.

\section{Tahap Aplikasi}

Tahap eksperimentasi yang telah dilakukan menghasilkan simbol-simbol berupa motifmotif, gatra, kalimat/lagu, serta pola ritme yang kemudian diseleksi dan diolah dalam kerja studio sesuai dengan kebutuhan. Tahap aplikasi sebagai kelanjutan dari tahap-tahap sebelumnya menghasilkan rancangan karya Pyang Pyung yang tersusun atas beberapa bagian yakni: introduksi, bagian I, bagian II, bagian III dan IV. Rancangan atau design ini terinspirasi dari tata urutan penyajian gending yang telah lama berlaku dalam kehidupan seni tradisi karawitan dimana gradasi struktur penyajian yang dilalui secara berurutan menunjukkan kerumitan yang bertingkat dari masing-masing bagian struktur penyajian.

Bagian introduksi merupakan pengenalan tema yang diwujudkan dengan presentasi musikal sederhana pada dua nada dengan menggunakan media musikal sederhana berupa suara gesekan dua buah instrumen rêbab yang dimainkan dalam pola ritme yang berbeda, dengan latar belakang suara instrumen slêntêm yang dimainkan dengan pola ritme sebagai berikut:

Teknik tabuhan minjal pada slêntêm:

666. 666. 666. 666.

Pengembangan tabuhan pinjalan pada slêntêm melalui beberapa metode aransemen yang meliputi filler (isian), diminusi (penyempitan), dan elise (pengurangan), maka terbentuklah motif tabuhan baru sebagai berikut:

$$
\begin{array}{llllllllll}
66 & \overline{6} & 6 & \overline{66} & \overline{66} & \overline{66} & \cdot 6 & \overline{.6} & \cdot 6
\end{array}
$$

Bagian ini mengeksplorasi dua nada yakni jangga dan nêm yang menggambarkan dalan rasa, rasaning dalan, dalaning rasa (Sastrapustaka, 1953). Melalui media bunyi ini penulis mengungkapkan tentang pentingnya rasa dalam hayatan suatu karya seni.

Rebab fade in (satu persatu dari rebab I, II, III) sebagai berikut:

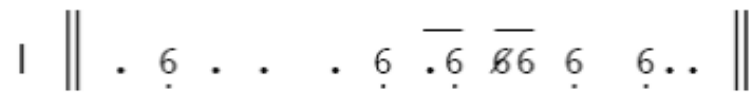

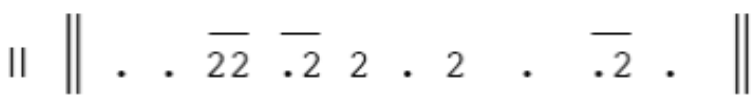

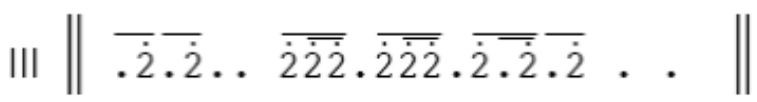

viola pick

$$
\|\overline{66.6 .6} \overline{.66} \overline{66} \overline{66} \cdot \overline{66} \cdot \overline{.6}\|
$$

Bagian I merupakan pengembangan pola kêmpyungjangga dan nêm dalam céngkok gênderan dêbyang-dêbyung dalam balutan pola ritmis hasil perpaduan perpaduan antara kêndang, kêmpul, suwukan, kêtuk, dan maracas. Pola tabuhan kêmpul dan suwukan membentuk back ground ritme yang menopang irama tabuhan céngkok dêbyang-dêbyung yang dihiasi dengan improvisasi kêndang agêng yang mengambil spirit kêndangan kosek wayangan yang dikombinasikan dengan isian-isian dan aksen-aksen yang terinspirasi oleh spirit kêndangan tari baris Bali. Keteraturan pola tabuhan instrumen kolotomis yang dinamis dan atraktif dalam konvensi tradisi dapat dijumpai pada struktur gending playon atau sampak. Struktur kolotomis pada playon inilah yang kemudian dikembangkan dengan cara substitusi tabuhan kênong menjadi tabuhan kêmpul dan suwukan.

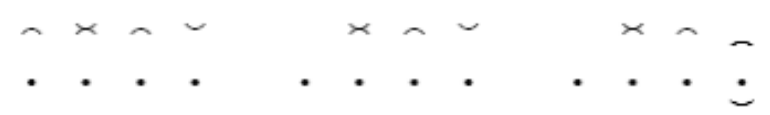

Kênong dan kêmpul pada pola tradisi di atas diubah menjadi kêmpul dan suwukan sebagai berikut:

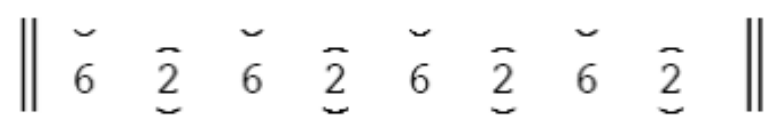


gender (debyang-debyung):

i $6 \quad i \quad 6 \quad i \quad \overline{6.5} \overline{\overline{.5 .5}} 6$

$\overline{321} \overline{\overline{26} \overline{12}} \overline{\overline{.321}} \overline{\overline{26} \overline{12}} \overline{\overline{.321}} \overline{2 \overline{35}} \overline{6 \overline{21}} \quad 6$

Pada bagian di atas permaianan maracas dan triangle menjadi bagian dari abstraksi keteraturan pola ritme tabuhan kêmpul dan suwukan.

Pada bagian II penulis menggunakan media perpaduan dua nada siliran melalui suara tabuhan instrumen kempyang sebagai disharmoni untuk membentuk kontras dari warna musikal bagian I. Motif lagu pokok yang diaktualisasikan melalui instumen sitêr dan flute merupakan hasil olah musikal dari gagasan yang diilhami oleh cengkok nduduk agêng pada instrumen gênder yang dikembangkan dengan teknik pelebaran gatra serta pemberian isian-isian nada pada bagian tengahnya, maka terwujudlah suatu motif lagu yang lebih panjang.

Gambang sebagai back sound:

561561561561561561561561561561

356356356356356356356356356356

Abstraksi melodi pokok (siter dan flute):

$\ldots 2356.6 .6 .63 .2 \ldots 2356.6 .6 .21 .6$

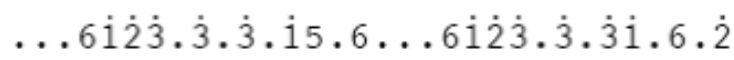

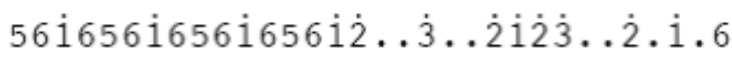

56i656i656i656i2..3..2iż..2.i.6

666 iiiiz2222iiii666666.......

Bagian III mempresentasikan nada-nada siliran melalui media beberapa instrumen yakni gong, suwukan, dan kêmpyang yang dilagukan secara bersama-sama. Syair vokal yang bersumber dari perspektif Sastra Laras terhadap dua nada penyusun kêmpyang, serta permaian salah satu sekaran kendang tradisi yang dibunyikan pada sisi kêmpyang-nya (bunyi sisi bem dihilangkan).

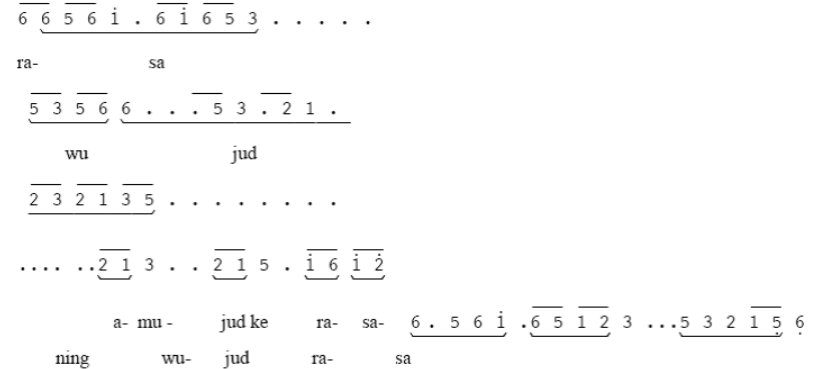

Sêkaran kêndangan kapang-kapang êncot:

$\bar{k} \circ \circ \overline{d b} \circ \overline{d b} \circ b \circ \overline{p l} \bar{\circ} \bar{b} \bar{l} \bar{l} t$

Dengan pengembangan melalui pemberian isian, pengurangan, pemendekan dan penambahan aksen maka terciptalah motif kêndangan yang lebih abstrak seperti berikut ini:

selingan isian kendang:

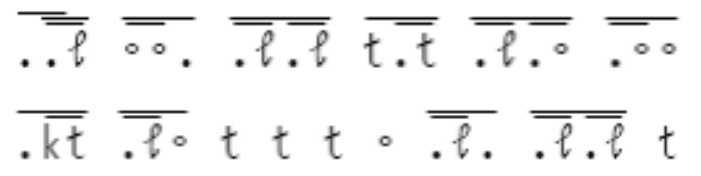

Bagian ini diteruskan dengan olah garap berbagai perpaduan dua nada yang dibawakan melalui instrumen gender dengan latar belakang pola ritme suwukan dibalut dengan suara duet siter yang memainkan cengkok gantungan nêm. Permainan gêndèr dengan sukat 6/8 yang menampilkan keterampilan pemain pada hampir semua bentuk perpaduan dua nada melalui pengembangan cengkok Jarik Kawung sebagai salah satu idiom klasik yang turut dipresentasikan dalam bagian ini.

Gêndèr:

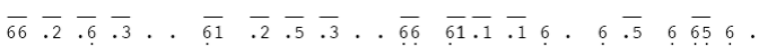

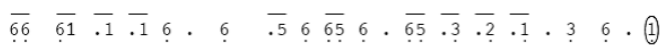

kêndang:

$b b t \overline{. b} . .6 b t \bar{b}$.

$b b t \overline{. b} \cdot \bar{t} \overline{p l} \quad b \quad b \quad t \overline{. b} \cdot \overline{\cdot t} \overline{\rho l}$

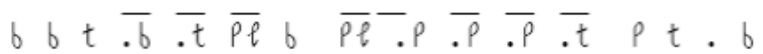

Bagian IV sebagai bagian klimaks dari komposisi Pyang Pyung menampilkan potensi perpaduan nada siliran sebagai hasil eksperimentasi instrumen pencon dalam pola ritme tertentu. Pada bagian ini, kempul, gong, dan kempyang ditempatkan sebagai pemangku irama, sedangkan masing-masing pemain yang lain menabuh dua 
pencon bonang dengan nada yang berurutan (siliran). Sebagai bagian puncak dari komposisi ini maka penulis mengoptimalkan intensitas siliran melalui perpaduan lima pasang pencon yang dimainkan secara bersamaan dengan pengolahan nilai kontras berdasarkan keras-lirih, cepat-lambat yang signifikan sebagai pembentuk dinamika musik pada bagian ending ini.

Pola tabuhan pencon:

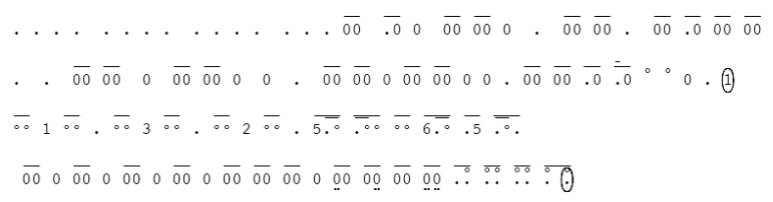

\section{Tahap Penyajian}

Secara teknis, pelaksanaan presentasi ini sama seperti halnya pergelaran karya seni musik pada umumnya. Sesuai dengan hakekat dari seni musik itu sendiri maka dalam presentasi ini penulis mengutamakan presentasi auditif karya seni musik melalui media utama suara instrumen, vokal maupun campuran antara instrumen dan vokal, sehingga penulis meminimalisir mediamedia non musik dalam menyampaikan pesan kepada audien. Presentasi karya komposisi ini menggunakan media utama gamelan jawa yang melibatkan 9 orang pemusik.

Guna memenuhi kebutuhan tata teknik pentas, maka penulis menerapkan konsep minimalis pada aspek-aspek seperti tata busana, tata lampu, tata setting panggung. Minimalisasi yang berarti menerapkan sesuatu sesuai dengan kebutuhan dimaksudkan agar tidak memecah fokus utama presentasi karya sesuai hakekatnya sebagai karya musik yang dinikmati melalui indera pendengaran.

\section{Penutup}

Terjadinya karya Pyang Pyung adalah melalui proses yang panjang dan bertahap, berawal dari munculnya gagasan, konsep, tema, dan penuangan. Berbagai bentuk pengembangan substansi dasar karawitan tradisi berdasarkan teknik dalam musik barat didukung oleh referensi musikalitas yang ada dalam diri penulis seiring dengan pengalamannya di bidang seni musik secara langsung, pada akhirnya mewujudkan sebuah karya komposisi karawitan dengan judul Pyang Pyung. Karya ini mempertemukan dua pola perpaduan nada siliran dan kêmpyung dalam musikalitas gamelan Jawa yang merepresentasikan bentuk keseimbangan eksistensi, potensi dan kontras dua hal berlawanan yang mampu membangun karakter, suasana, dan dinamika dalam suatu sajian komposisi karawitan.

Karya Pyang Pyung merupakan suatu pembuktian bahwa proses penciptaan seni yang diawali dari subjek kecil yang lokal, sederhana, atau dianggap biasa, ternyata dapat menghasilkan sebuah karya komposisi karawitan. Penulis yakin bahwa di dalam seni karawitan masih terdapat banyak potensi ter-sembunyi yang dapat digali dari objek yang sifatnya kecil, sederhana, sêpele dan lokal untuk diangkat sebagai subjek dalam dunia penciptaan seni musik Nusantara. Sensitivitas terhadap potensi objek-objek kecil akan memberikan dampak positif upaya pelestarian seni budaya warisan nenek moyang.

\section{Kepustakaan}

Hastanto, S. (1997). Pendidikan Karawitan Situasi Problema dan Angan-angan. Wiled.

Prasetya, H. B. (2006). Gembyang dan Kempyung dalam Karawitan Gaya Yogyakarta: Tinjauan Fisika Bunyi. EKSPRESI Jurnal Penelitian dan Penciptaan Seni, 7(1): 65 - 77.

Saepudin, A. (2015). Laras, Surupan, dan Patet dalam Praktik Menabuh Gamelan Salendro. RESITAL: JURNAL SENI PERTUNJUKAN, 16(1): 52 .

Sastrapustaka, B.Y.H. (1953). Wedha Pradangga Kawedhar. (manuskrip) Yogyakarta

Salim, A. (2010). Musik Adaptasi Dangdut dalam Ansambel Perkusi. RESITAL: JURNAL SENI PERTUNJUKAN,11(2): 106 -123.

Supanggah, R. (2009). Bothekan Karawitan II. Surakarta: Program Pasca Sarjana

Subawa, Y. (2007). Salah Gumun. [Tesis]. Program Pascasarjana Institut Seni Indonesia Surakarta. Warsana. (2012). Tumpang Tindhih : Sebuah Komposisi Musik dalam Interpretasi Personal. RESITAL: JURNAL SENI PERTUNJUKAN,13(1): 74-94. 